\title{
Heavy Positive Ion Groups in Titan's Ionosphere from Cassini Plasma Spectrometer IBS Observations
}

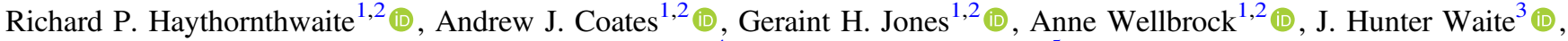 \\ Véronique Vuitton ${ }^{4}$ (10), and Panayotis Lavvas ${ }^{5}$ (10) \\ ${ }^{1}$ Mullard Space Science Laboratory, Department of Space and Climate Physics, University College London, Dorking, UK; richard.haythornthwaite.18@ucl.ac.uk, \\ richardhaythornthwaite@hotmail.co.uk \\ ${ }^{2}$ The Centre for Planetary Sciences at UCL/Birkbeck, London, UK \\ ${ }^{3}$ Space Science and Engineering Division, Southwest Research Institute, San Antonio, TX 78228, USA \\ ${ }^{4}$ Institut de Planétologie et d'Astrophysique de Grenoble, Univ. Grenoble Alpes, CNRS, Grenoble F-38000, France \\ ${ }^{5}$ Université de Reims Champagne Ardenne, CNRS, GSMA UMR 7331, F-51097 Reims, France \\ Received 2020 September 18; revised 2020 December 11; accepted 2020 December 14; published 2021 February 9
}

\begin{abstract}
Titan's ionosphere contains a plethora of hydrocarbons and nitrile cations and anions as measured by the Ion Neutral Mass Spectrometer and Cassini Plasma Spectrometer (CAPS) on board the Cassini spacecraft. Data from the CAPS Ion Beam Spectrometer (IBS) sensor have been examined for five close encounters of Titan during 2009. The high relative velocity of Cassini with respect to the cold ions in Titan's ionosphere allows CAPS IBS to function as a mass spectrometer. Positive ion masses between 170 and $310 \mathrm{u} / \mathrm{q}$ are examined with ion mass groups identified between 170 and $275 \mathrm{u} / \mathrm{q}$ containing between 14 and 21 heavy (carbon/nitrogen/oxygen) atoms. These groups are the heaviest positive ion groups reported so far from the available in situ ion data at Titan. The ion group peaks are found to be consistent with masses associated with polycyclic aromatic compounds (PAC), including polycyclic aromatic hydrocarbon $(\mathrm{PAH})$ and nitrogen-bearing polycyclic aromatic molecular ions. The ion group peak identifications are compared with previously proposed neutral PAHs and are found to be at similar masses, supporting a PAH interpretation. The spacing between the ion group peaks is also investigated, finding a spacing of 12 or $13 \mathrm{u} / \mathrm{q}$ indicating the addition of $\mathrm{C}$ or $\mathrm{CH}$. Lastly, the occurrence of several ion groups is seen to vary across the five flybys studied, possibly relating to the varying solar radiation conditions observed across the flybys. These findings further the understanding between the low-mass ions and the high-mass negative ions, as well as with aerosol formation in Titan's atmosphere.
\end{abstract}

Unified Astronomy Thesaurus concepts: Ionosphere (860); Planetary atmospheres (1244); Planetary science (1255); Saturnian satellites (1427)

\section{Introduction}

Titan is the largest moon of Saturn and the only known moon in the solar system with a dense atmosphere. Since its discovery by Christiaan Huygens, it has been observed using both telescopes and spacecraft including the Pioneer 11, Voyager $1 \& 2$ spacecraft and most recently Cassini-Huygens. Data from the Voyager flybys revealed Titan to possess a thick atmosphere $(150 \mathrm{kPa})$ rich in nitrogen and hydrocarbon compounds (Tyler et al. 1981; Lindal et al. 1983). During Cassini's tour of the Saturnian system between 2004 and 2017 the Cassini spacecraft performed over 100 flybys of Titan, taking in situ measurements of its ionosphere and upper atmosphere. These in situ measurements helped demonstrate the connection between ion-neutral reactions generating large charged molecules in the upper atmosphere and the formation of aerosols (Waite et al. 2005, 2007; Coates et al. 2007).

Titan's atmosphere is nitrogen rich (95\%-98\%) and contains minor species of methane $(2 \%-5 \%)$ and hydrogen $(0.1 \%)$. A plethora of trace species exist including hydrocarbons, nitriles, and oxygen-bearing molecules such as carbon dioxide and carbon monoxide (Coustenis et al. 2007; Waite et al. 2005). The oxygen-bearing molecules are thought to originate from

\footnotetext{
cC (i) Original content from this work may be used under the terms of the Creative Commons Attribution 4.0 licence. Any further distribution of this work must maintain attribution to the author(s) and the title of the work, journal citation and DOI.
}

$\mathrm{O}^{+}$ions and micrometeorites entering Titan's atmosphere (Hartle et al. 2006; Hörst et al. 2012).

Noticeable features of Titan's atmosphere are the haze layers that give rise to the moon's orange appearance. The layers are optically thick in most visible wavelengths making remote observations of Titan's surface difficult (Porco et al. 2005). The organic haze is made up of aerosols and from early experiments using $\mathrm{N}_{2} / \mathrm{CH}_{4}$ mixtures, a combination of polycyclic aromatic hydrocarbons (PAHs) and polycyclic aromatic nitrogen heterocycles (PANHs) was proposed as the composition of the aerosols (Sagan et al. 1993). The detection of benzene from both remote sensing (Coustenis et al. 2003) and in situ (Waite et al. 2007) measurements supported this interpretation, benzene being an aromatic precursor to larger PAHs. Early Titan flybys identified possible heavy PAH ions such as naphthalene, anthracene derivatives, and an anthracene dimer at 130,170, and $335 \mathrm{u} / \mathrm{q}$ respectively (Waite et al. 2007) and these are thought to be formed through ion-molecule reactions in the upper atmosphere (Westlake et al. 2014). Remote sensing infrared measurements have also suggested the presence of PAHs/PANHS up to several hundred amu in the atmosphere (López-Puertas et al. 2013).

Previous ion composition studies by the Ion and Neutral Mass Spectrometer (INMS) and Cassini Plasma Spectrometer (CAPS) instruments revealed "families" of ions around particular mass values and a regular spacing of 12-14 u/q between mass group peaks characteristic of spectra of complex organic compounds and related to a carbon or nitrogen backbone that dominates the ion 
chemistry (Waite et al. 2005; Cravens et al. 2006; Vuitton et al. 2007; Crary et al. 2009). Early Titan flybys by Cassini revealed positive ion masses up to $350 \mathrm{u} / \mathrm{q}$, obtained using measurements from the CAPS Ion Beam Spectrometer (Waite et al. 2007). Later flybys demonstrated the existence of even larger positive ions up to $1100 \mathrm{u} / \mathrm{q}$ (Coates et al. 2010). In addition to positive ions, negative ions have been detected in Titan's ionosphere (Coates et al. 2007). These negative ions extend to higher masses than the positive ions with masses up to $13,800 \mathrm{u} / \mathrm{q}$ (Coates et al. 2009; Wellbrock et al. 2013, 2019). The negative ions are thought to be composed of carbon chains, with the higher masses having a suspected PAH/PANH composition (Coates et al. 2007; Desai et al. 2017).

The studies by Crary et al. (2009); Mandt et al. (2012) and Westlake et al. (2014) used IBS data to study various aspects of ion composition at Titan. These compositional studies covered positive ions (1-200 u/q) in Titan's ionosphere and showed that the likely origin of the ions above $100 \mathrm{u} / \mathrm{q}$ were aromatic compounds created through ion-molecule reactions. Crary et al. (2009) discuss possible ion composition for mass groups up to $\mathrm{C} 13$, where $\mathrm{C} 13$ indicates the mass group where there are 13 "heavy" (carbon, nitrogen, or oxygen) atoms present. The heaviest mass group they reported was the $\mathrm{C} 15$ group although the possible ion composition of this material was not discussed.

There have been several experimental efforts to replicate the organic haze present at Titan along with measurements of the ionmolecule gas-phase chemistry (Dubois et al. 2020). Some of these experiments have measured products up to $400 \mathrm{amu}$ (Berry et al. 2019). Chemical models based on CAPS measurements have proposed molecules up to the $\mathrm{C} 17$ group using a mechanistic approach to explain the carbocation/carboanion chemistry (Ali et al. 2015). The schemes studied included hydrocarbons and nitriles and various reaction paths for the growth of these molecules.

Ions with masses between 170 and $310 \mathrm{u} / \mathrm{q}$ are examined in this study with ion mass groups identified up to $275 \mathrm{u} / \mathrm{q}$. Prominent groups identified contain 15, 16, 18, and 21 heavy atoms. Several ion groups also show variation in their occurrence between flybys.

\section{Methodology}

\subsection{Cassini Plasma Spectrometer}

The Cassini spacecraft carried a full suite of scientific instruments including fields, waves, remote sensing, neutral, and ion particle instruments. One of these instruments was the CAPS instrument which studied ions and electrons using three electrostatic analyzers mounted on an actuating platform. CAPS was in operation up to 2011 and a short time during 2012. The three CAPS sensors were the Electron Spectrometer (ELS), Ion Mass Spectrometer (IMS) and the Ion Beam Spectrometer (IBS).

Only data from CAPS IBS were used for the present study. CAPS IBS is a curved-electrode electrostatic analyzer and measures ion flux as a function of kinetic energy and direction (Young et al. 2004). The ions enter the sensor through three entrance fans (Field of View, $150^{\circ} \times 1.4$ ) which are tilted at $30^{\circ}$ to each other. The energy resolution of IBS is $0.014 \Delta E / E$ and during the Titan encounters, the sensors swept from $207 \mathrm{eV}$ down to $3 \mathrm{eV}$ through 255 adjacent energy bins (Young et al. 2004). As CAPS is mounted on an actuating platform, IBS can be rotated to increase its field of view but for the interest of this study we have focused on the Titan flybys where CAPS was at fixed actuation. This direction is approximately in the $-X$ direction in the spacecraft frame and is aligned with the view direction of INMS. By using flybys where CAPS has a fixed actuation in the ram direction more data points can be obtained throughout the flyby.

\subsection{Data Analysis and Ion Winds}

The first stage of the analysis was running a peak finding algorithm on each IBS energy sweep over a flyby. An example of one energy sweep can be seen in Figure 1. A peak was defined as any bin with a count number above the noise level of the instrument as well as above the Poisson counting error, i.e., the square root of the count number, when compared with adjacent energy bins. This was repeated across a flyby, Figure 2 shows the peaks identified during the T59 flyby over plotted on a spectrogram.

During the Titan flybys, Cassini had a high velocity $\left(6 \mathrm{~km} \mathrm{~s}^{-1}\right)$ relative to the low ion thermal $(150 \mathrm{~K})$ and wind velocities $\left(<230 \mathrm{~m} \mathrm{~s}^{-1}\right)$ in the ionosphere (Crary et al. 2009). The combination of these factors means that the ions appear as a highly-directed cold supersonic beam in the spacecraft frame. The ions therefore appear at kinetic energies associated with the spacecraft velocity and ion mass and therefore the measured $\mathrm{eV} / \mathrm{q}$ spectrum can be converted to a $\mathrm{u} / \mathrm{q}$ spectrum. Under the assumption of singular charged ions, the $\mathrm{u} / \mathrm{q}$ spectrum can be interpreted as an u spectrum.

In environments such as Titan's ionosphere where the ion temperatures are low, the expected peak flux for an ion species $\alpha$, occurs at energy $E_{\alpha}$ as approximated by Equation (1) (Crary et al. 2009; Mandt et al. 2012; Westlake et al. 2014),

$$
E_{\alpha}=\frac{1}{2} m_{\alpha}\left(v_{\mathrm{sc}}+v_{\mathrm{wind}}\right)^{2}+e \Phi_{\mathrm{sc}}+8 k T .
$$

Equation (1) takes into account various effects that alter the peak energy flux such as ion temperature $(8 \mathrm{kT})$, spacecraft potential $\left(\mathrm{e} \Phi_{\mathrm{sc}}\right)$ and ion wind $\left(v_{\text {wind }}\right)$. Through the inversion of Equation (1) we can find a mass associated with each peak in the energy spectra. The width of each beam is roughly equal to the thermal velocity of the ions, as described by Equation (2),

$$
\frac{M}{\Delta M} \approx \frac{v_{\mathrm{sc}}+v_{\mathrm{wind}}}{\sqrt{\frac{2 k T}{m_{\alpha}}}} .
$$

Spacecraft charging can affect the energy/charge of the particles measured by CAPS sensors. Spacecraft potential values are inferred from another Cassini instrument, the Radio and Plasma Wave Science (RPWS) Langmuir probe (Gurnett et al. 2004). A constant offset between the Langmuir probe and CAPS IBS of $+0.2 \pm 0.15 \mathrm{~V}$ has been found by previous studies (Crary et al. 2009; Westlake et al. 2011; Mandt et al. 2012). For this study interpolated Langmuir probe potentials were used with an applied offset of $+0.2 \mathrm{~V}$. Also, a fixed temperature of $150 \mathrm{~K}$ was applied during the analysis. This value is representative of the temperatures seen in Titan's ionosphere which are between 100 and $200 \mathrm{~K}$ (Crary et al. 2009).

Examining the magnitudes of the three terms in Equation (1) the dominant parameter is the ion wind. Taking the highest reported ion wind value of $260 \mathrm{~ms}^{-1}$, this would represent a $9 \%$ shift in the ion kinetic energy, i.e. $2.8 \mathrm{eV}$ shift for a $31.9 \mathrm{eV}$ ion, which are the lightest ions examined in this study. The spacecraft potential term typically is between -0.5 and $-2 \mathrm{eV}$ (Crary et al. 2009). $2 \mathrm{eV}$ represents a $6 \%$ energy shift for a $31.9 \mathrm{eV}$ ion. Lastly, 




Figure 1. Example of an IBS energy spectra during the T57 flyby. The error bars shown represent the uncertainty due to Poisson counting error. Red x's indicate the peaks as identified by the peak finding algorithm. Due to the logarithmic energy scale, at low energies the ion beams can be seen over a number of bins, while at the high masses the beams can only be seen in a single bin.

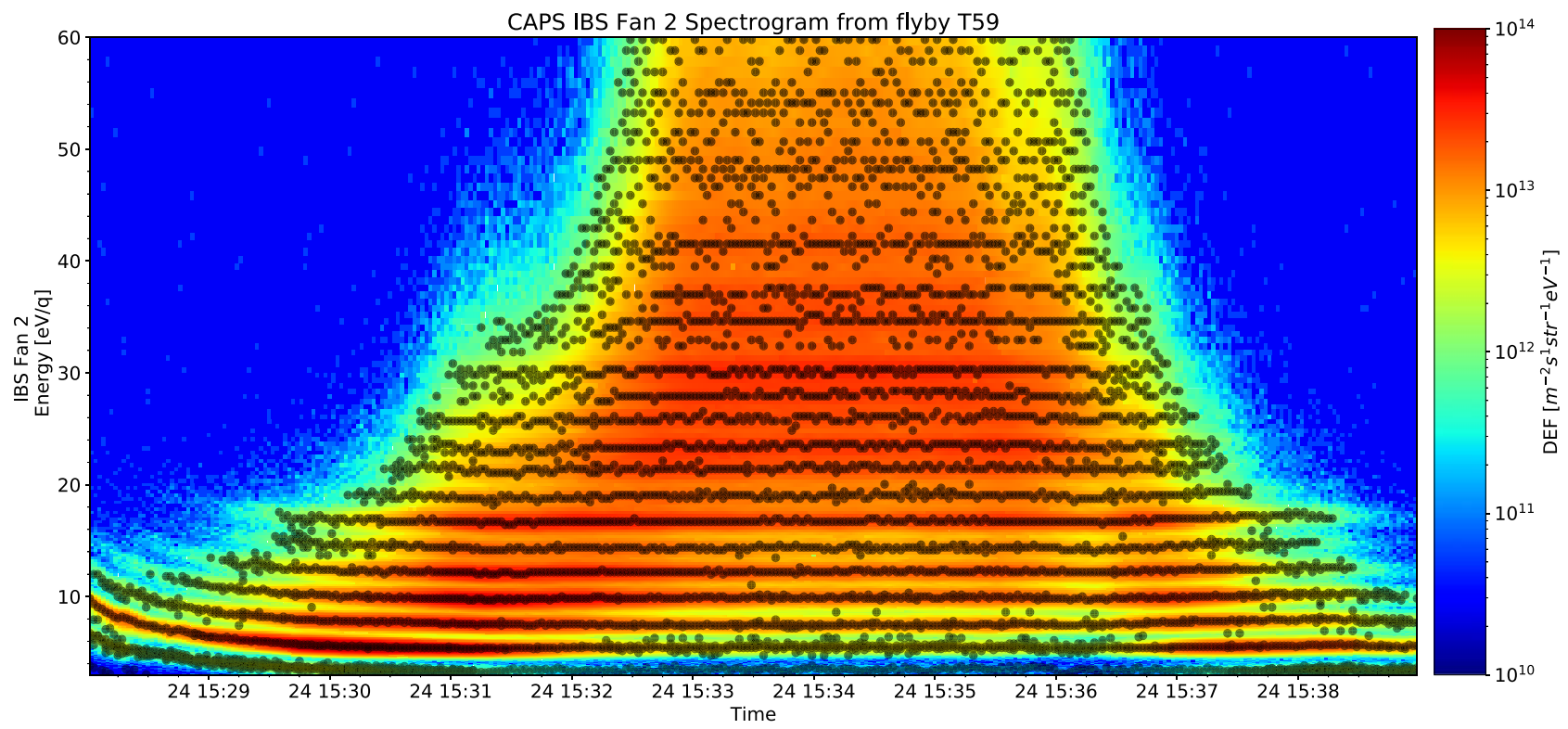

Figure 2. Energy/charge spectrogram from the T59 Titan flyby with intensity shown in differential energy flux. Peaks identified by the algorithm are over plotted with dots. The mass groups identified can clearly be seen by the horizontal lines of dots. Small variations in the energy of the identified peaks are due to effects such as ion velocity, spacecraft potential, and slight shifts in spacecraft orientation. The energy shift on the inbound leg of the flyby (before 15:30) is due to the acceleration of ions away from Titan.

an ion temperature of $150 \mathrm{~K}$ corresponds to a $0.1 \mathrm{eV}$ shift, a $0.3 \%$ shift for a $31.9 \mathrm{eV}$ ion. As seen in Equation (1), the ion temperature and spacecraft potential terms are not mass dependent, implying that for higher mass ions the energy shifts due to the ion temperature and spacecraft potential terms decrease as a proportion of the measured energy $E_{\alpha}$.

The ion wind calculation relies on previously identified major peaks. The determination for which peaks to use was influenced by the work of Mandt et al. (2012), who used the
INMS instrument to calculate ion densities. The three major peaks used in this study were the 28,39 , and $91 \mathrm{u} / \mathrm{q}$ peaks, these ions were used as they were found to be the most abundant ions within their respective mass groups (Mandt et al. 2012).

These peaks can be used to estimate the ion winds that are present in Titan's upper atmosphere and ionosphere. The winds affect the detected energy of the ions by shifting the energy at which they peak in each spectrum as seen in Equation (1). To 
construct mass spectra from the ion data this effect must be accounted for. Using the previously stated abundant ions we can calculate the ion wind by using a "mass-dependent effective spacecraft potential" defined as (Crary et al. 2009),

$$
\Phi^{\prime} \approx \Phi+\frac{m v_{\mathrm{sc}}}{e} v_{\mathrm{wind}},
$$

and by differentiating we find

$$
v_{\mathrm{wind}}=\frac{e}{v_{\mathrm{sc}}} \frac{d \Phi^{\prime}}{d m}
$$

where $\Phi$ is the spacecraft potential, $\Phi^{\prime}$ is the effective spacecraft potential, $v_{\mathrm{sc}}$ is the spacecraft velocity and $v_{\text {wind }}$ is the along track ion wind velocity. By finding the effective spacecraft potential corrections for the three major mass peaks to be at their observed energies and calculating the gradient, the ion wind can be found using Equation (4).

\subsection{High-mass Methodology and Uncertainties}

A full analysis of the ions would require convolutions of the ion distributions at separate masses with the IBS energy response and then a subsequent fit to the observed data. At the high masses studied here this becomes impractical as a result of the limited ability to resolve different masses due to the $\Delta E / E$ energy resolution at FWHM of the IBS sensor. IBS was designed with a $\Delta E / E$ of 0.014 (Young et al. 2004) and calibration tests measured a $\Delta E / E$ of 0.02 (Vilppola et al. 2001). Here we use a $\Delta E / E$ of 0.017 , which was the operational $\Delta E / E$ value (Young et al. 2004) and was used in Crary et al. (2009). A $\Delta E / E$ of 0.017 results in the effective $M / \Delta M$ mass resolution being limited to $<60$ by the instrument's energy response.

How the energy resolution acts as a limiting factor is shown in Figure 3. The top panel is representative of a low-mass ion beam as observed by IBS, while the middle and lower panels show high-mass ion beams observed by IBS. As can be seen in the top panel, the low-mass ion beam can be well resolved across multiple energy bins. The sequences of blue peaks in Figure 3 can be compared with the first peak in Figure 1, as both represent beams with similar ion masses. The peak in Figure 1 appears across more bins due to the logarithmic scaling.

In contrast, the middle and lower panels show beams relating to ion masses of 214 and $217 \mathrm{u} / \mathrm{q}$, both of which could cause a peak in the same IBS energy bin. From this it could be concluded that the same methodology can be applied to both low and high masses, but comparing with Figure 1 we can see this is not the case. At the high energies around 40 and $50 \mathrm{eV} /$ $\mathrm{q}$, the beams are not resolved over three or four bins, with some peaks displaying similar intensity on either side of the peak. This means that the fitting cannot be performed over several peaks and we are left to conclude that any ion mass that generates an ion beam with a peak energy within the FWHM of the energy bin is plausible. Returning to the middle and bottom panels of Figure 3, this means any mass between 214 and 217 $\mathrm{u} / \mathrm{q}$ can generate a peak in the energy bin centered around $40.2 \mathrm{eV} / \mathrm{q}$, thus creating the uncertainty in our mass resolution.

After the peaks in the energy spectra were found and converted to mass spectra, the masses were binned at a $1 \mathrm{u} / \mathrm{q}$ resolution, similar to that done by Crary et al. (2009). This process does not generate a mass spectrum where one can analyze fragmentation patterns but shows which cations are more abundant than cations of neighboring masses.

The total mass uncertainty is calculated by adding in quadrature the uncertainty from the energy resolution and the uncertainty resulting from the $1 \mathrm{u} / \mathrm{q}$ binning process. The energy resolution dominates the total uncertainty, being \pm 2 or $\pm 3 \mathrm{u} / \mathrm{q}$ compared with $\pm 0.5 \mathrm{u} / \mathrm{q}$ from the binning.

\subsection{Studied Flybys}

The five flybys studied all occurred in 2009, all with similar characteristics such as Solar Zenith Angle (SZA), latitude, and longitude as can be seen in Table 1. CAPS was at a fixed actuation during these five flybys, meaning that rammed ionospheric ions were measured across the entire flyby, resulting in a greater number of data points than the previous actuating flybys. The times when Cassini exited Titan's shadow can also be seen in the table. In total 448 energy sweeps were used covering altitudes from 955 to $1001 \mathrm{~km}$. There is variation in the solar illumination conditions between the data used from the flybys. The data selected from T55 was almost entirely in Titan's shadow, while T59 was illuminated the entire time with the other flybys containing a mixture.

\section{Results}

Through the use of the previously described algorithm across the 448 CAPS IBS energy sweeps, the occurrence of mass groups and the group peaks can be studied. Shown in Figure 4(a) is every peak identified across the five flybys, plotted against altitude. The previously found trend of heavier ions occurring at lower altitudes (Crary et al. 2009) can be seen. Figure 4(b) displays the peaks between 200 and $300 \mathrm{u} / \mathrm{q}$ and below $1000 \mathrm{~km}$. With this plot several groups can be seen with distinct ion clustering around 203, 217, 228, 241, and 266 u/q. The T57 and T59 flybys have closest approaches of 955 and $957 \mathrm{~km}$, around $10 \mathrm{~km}$ lower than the other three flybys that can be seen in the figure.

The low-mass ions from $0-100 \mathrm{u} / \mathrm{q}$ have been well studied by both the CAPS and INMS instruments (Mandt et al. 2012; Westlake et al. 2014). Groups of intermediate mass (100-200 $\mathrm{u} / \mathrm{q}$ ) positive ions were found along with major peaks with a 12-14 u/q spacing between peaks. This study focuses on the high masses between 170 and $310 \mathrm{u} / \mathrm{q}$ outside the mass range of the INMS instrument. The structure is less clearly defined than the lower mass ranges and therefore only mass groups and significant peaks are focused on in this study.

\subsection{Previously Reported Ion Groups (100-200 u/q)}

For the comparison with Crary et al. (2009), after the peaks were found in the energy spectra and converted to mass values, the mass values were binned at a $1 \mathrm{u} / \mathrm{q}$ resolution. Then the number of occurrences of a peak in each $1 \mathrm{u} / \mathrm{q}$ bin across the five flybys was summed and then divided by the total number of sweeps examined across the flybys. This generates a percent occurrence value, representing how often a peak occurred in the studied data and is shown by the black line in Figure 5. Eight mass groups were found in the 100-200 u/q mass range with each group being centered around a significant peak. For comparison, the percent occurrence found by Crary et al. (2009) is shown by the blue line.

This comparison is necessary due to this study applying different methodology than that applied previously in Crary et al. (2009). 

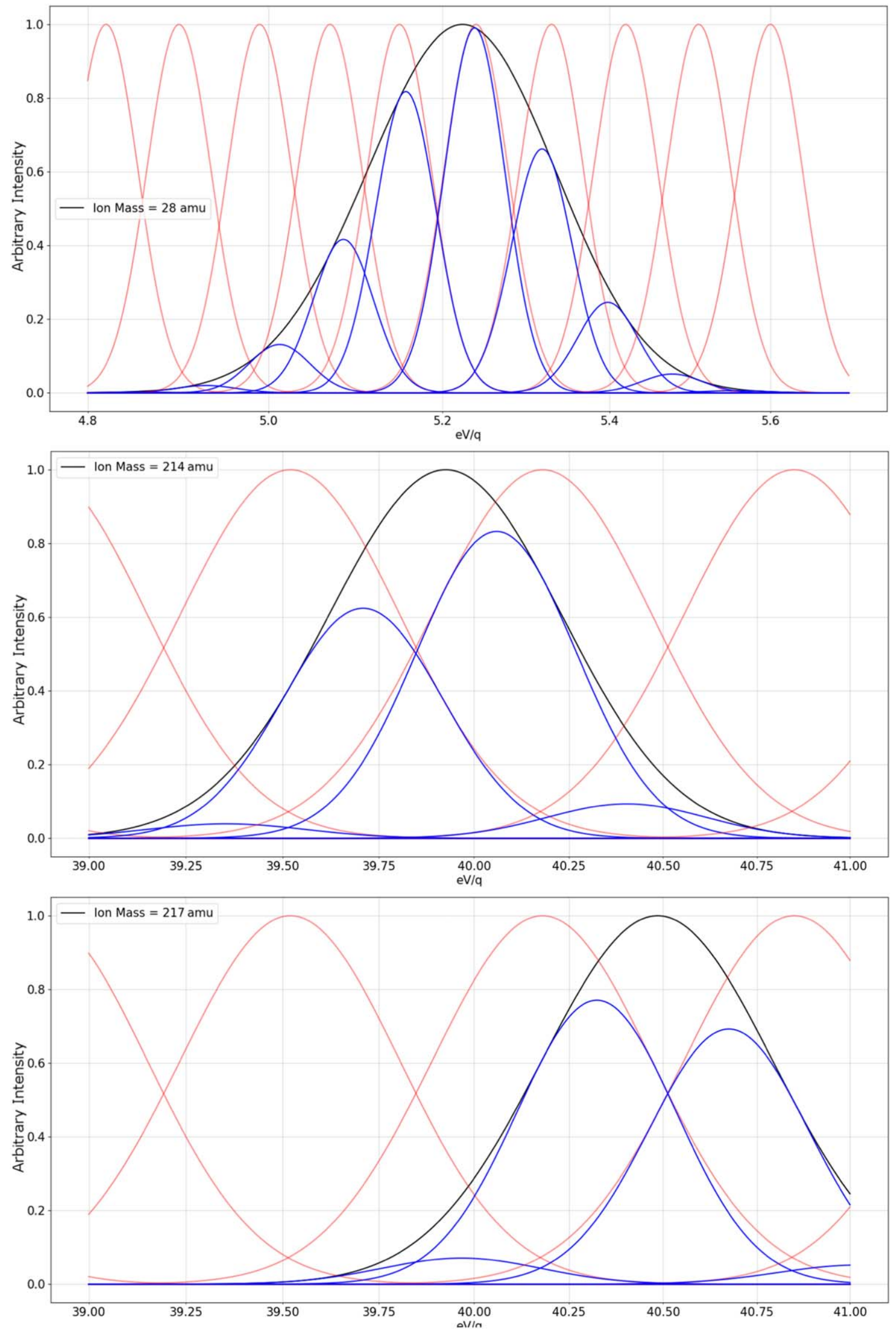

Figure 3. These three panels are used to illustrate the difference between observing low-mass and high-mass ion beams with the IBS sensor. For all three panels, the red lines represent the IBS response, with each Gaussian curve representing a different IBS energy bin. The black line represents an observed ion beam, idealized with a Gaussian and the width being determined by Equation (2). The blue lines are each of the IBS energy bins (red) multiplied by the ion beam (black) and are representative of the spectra generated by IBS. 
Table 1

Table Displaying the Data Used in this Study

\begin{tabular}{|c|c|c|c|c|c|c|c|c|c|}
\hline Flyby & UTC Times & Titan Shadow Exit UTC Time & Number of Sweeps & Min Altitude $(\mathrm{km})$ & Max Altitude $(\mathrm{km})$ & $\operatorname{Lat}\left({ }^{\circ}\right)$ & $\overline{2 \operatorname{Long}\left({ }^{\circ}\right)}$ & SZA Range $\left({ }^{\circ}\right)$ & Titan Local Time \\
\hline T55 & $21: 25: 13-21: 28: 08$ & 21:28:06 & 88 & 966 & 1001 & -19.1 & 176.1 & 134-149 & $22: 00: 27$ \\
\hline T56 & 19:58:37-20:01:21 & 20:00:19 & 83 & 967 & 1000 & -28.0 & 175.4 & $127-143$ & $22: 00: 57$ \\
\hline T57 & 18:30:57-18:34:09 & $18: 31: 37$ & 97 & 955 & 1000 & -34.9 & 173.1 & $119-137$ & 22:07:31 \\
\hline $\mathrm{T} 58$ & $17: 02: 39-17: 05: 25$ & $17: 01: 21$ & 84 & 966 & 999 & -44.7 & 172.4 & $112-128$ & $22: 07: 42$ \\
\hline T59 & $15: 32: 26-15: 35: 39$ & $15: 29: 03$ & 96 & 957 & 1000 & -54.7 & 171.6 & $103-120$ & 22:08:20 \\
\hline
\end{tabular}

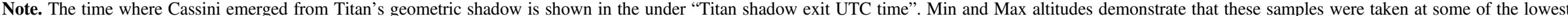

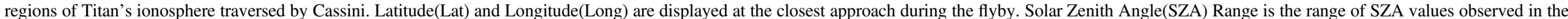
sample range. Titan Local Time is shown in the last column. 

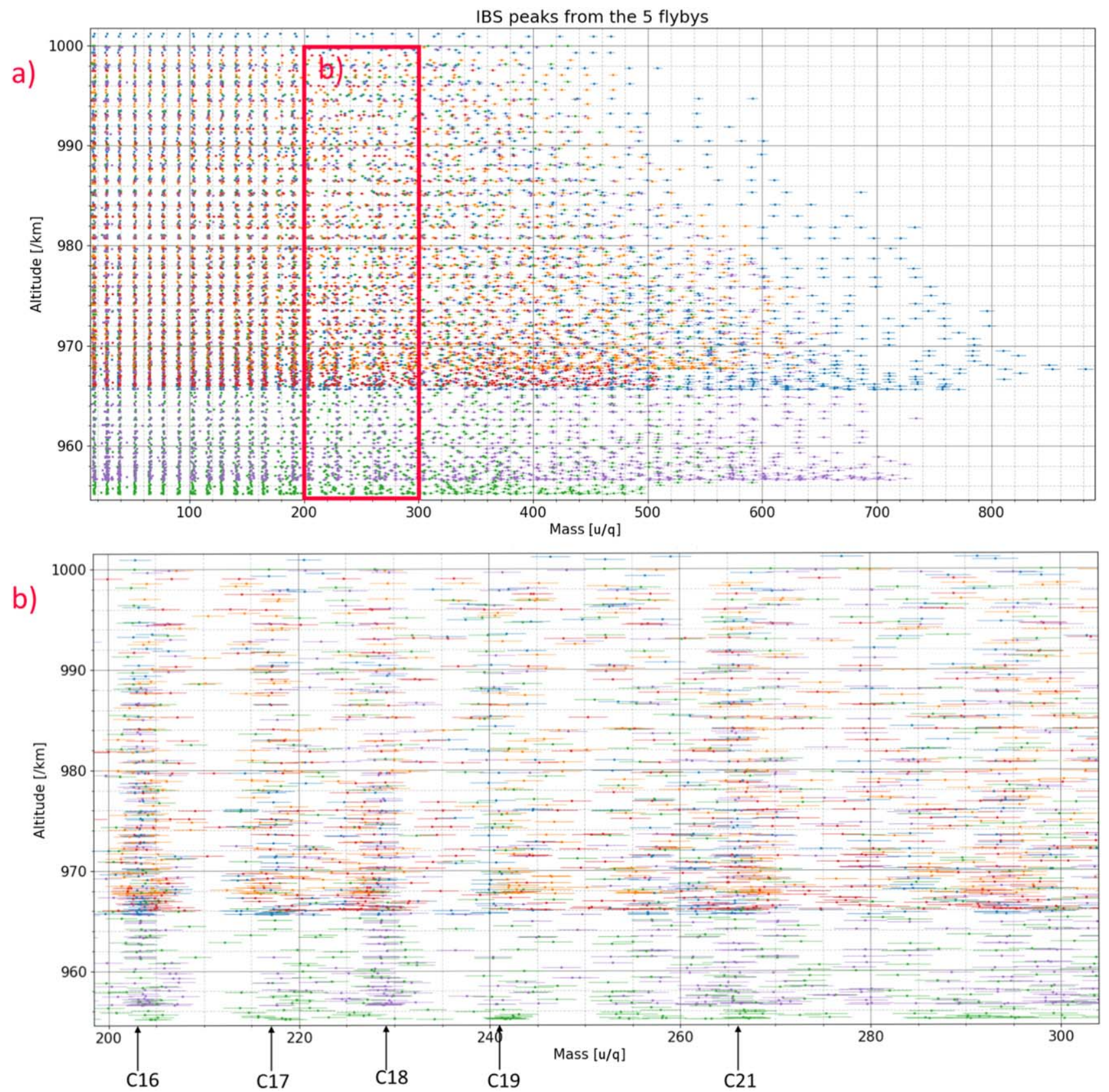

Figure 4. (a) Altitude-mass plot for every peak identified by the peak finding algorithm at the altitudes examined. The error bars represent the instrument uncertainty for the peak detection. Each color represents a different flyby, T55-blue, T56 - orange, T57-green, T58—red, T59-purple. Panel (b) is a section of panel (a) between 200 and $300 \mathrm{u} / \mathrm{q}$. Clear grouping of ions can be seen, notably around 203, 217, 229, 241, and $266 \mathrm{u} / \mathrm{q}$.

The main difference is that the cross-calibration between INMS and IBS data was not performed in this study, but was applied in the previous Crary et al. (2009) study. The comparison helps to link the existing study to the higher mass resolution measurements of INMS. Other differences include the mass peaks found by Crary et al. (2009) being derived from interpolating the energy spectra to $1 \mathrm{u} / \mathrm{q}$ mass bins using fit determined parameters and then identifying peaks. Lastly, Crary et al. (2009) studied flybys up to 2008 January and this study examines flybys during 2009, therefore, a comparison at this mass range is useful to check for variation with time.

Although there are methodology differences this study reproduces the mass peaks identified by Crary et al. (2009) fairly accurately. Agreement between the new methodology and previous work gives us confidence that the cross-calibration is not necessary for this study and to extend the method to study high-mass ions above $200 \mathrm{u} / \mathrm{q}$.

\subsection{High-mass Ions (170-310 u/q)}

The high-mass ions and the mass group structure is displayed in Figure 6. The mass group numbering $(\mathrm{C \#})$ indicates the number of heavy atoms (carbon/nitrogen/ oxygen) present. Clear structure can be seen for the C14 to C19 groups, corresponding to masses between 172 and $251 \mathrm{u} /$ q. These groups have a major peak and well-defined troughs between the groups. Furthermore, below $251 \mathrm{u} / \mathrm{q}$ the spacing between peaks of 12-14 u/q agrees with the trend observed at lower masses. 


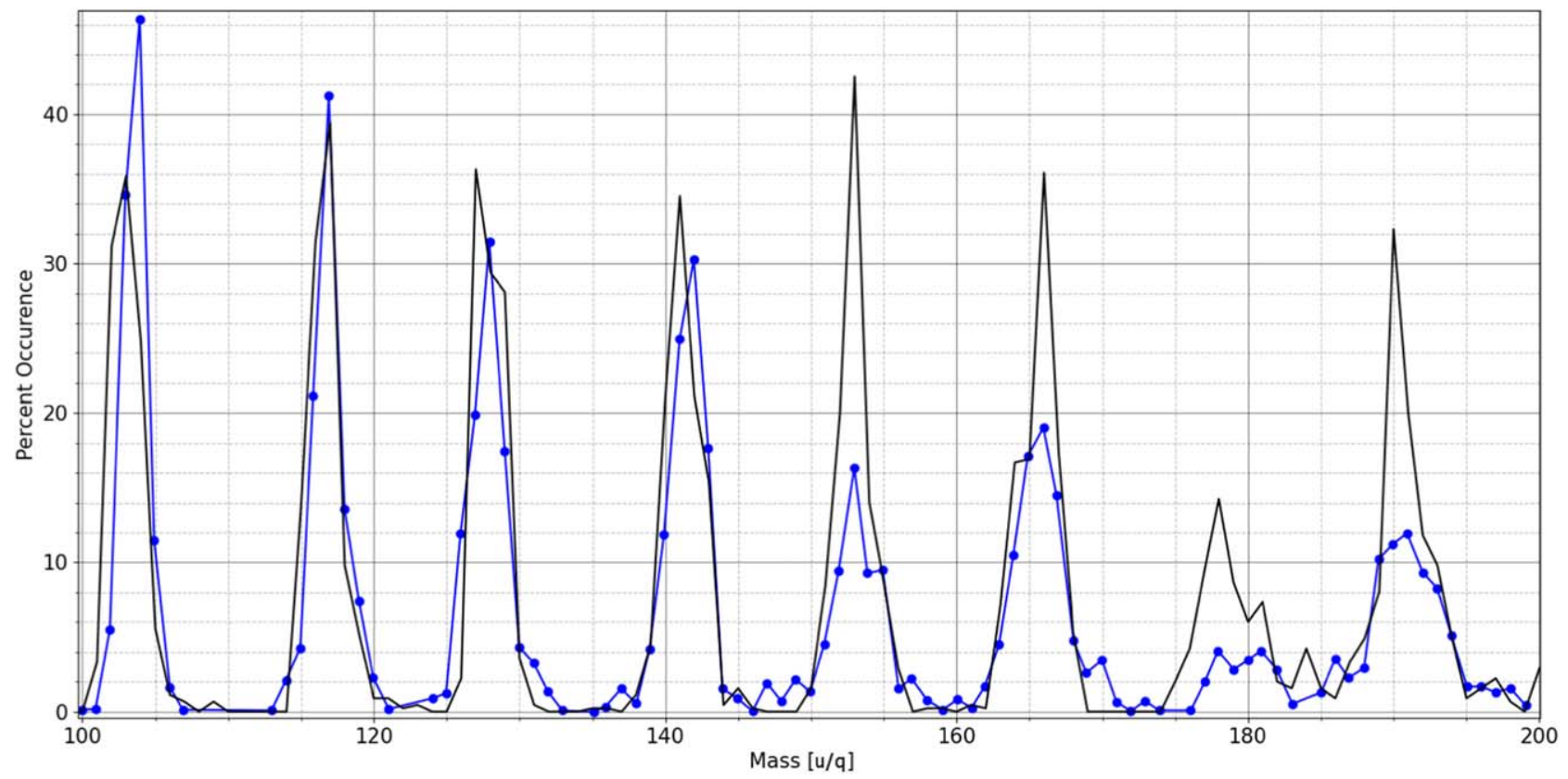

Figure 5. Black line represents the summed percent occurrence of the peaks over the flybys with $1 \mathrm{u} / \mathrm{q}$ binning from the present study. The blue line represents the percent occurrence from Crary et al. (2009). Good agreement can be seen, with the present study showing more defined peaks for the ion groups around 180 and 190 u/q.
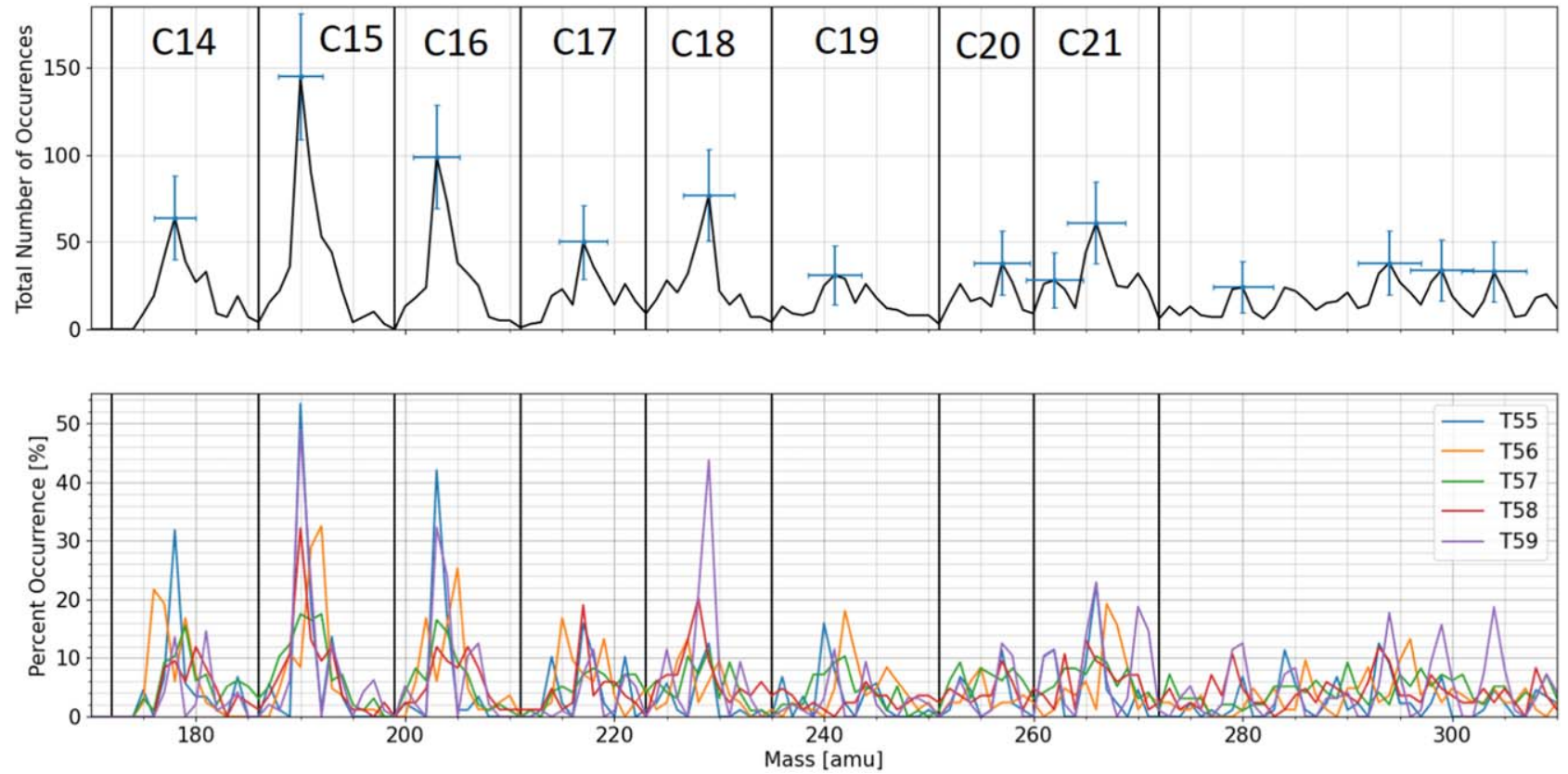

Figure 6. Top panel displays the total number of times a peak occurs in each $1 \mathrm{u} / \mathrm{q}$ bin. Vertical lines indicate the boundaries between the different ion groups, with the boundaries being defined by local minima in the total number of occurrences. Each group is labeled with C\#, where \# indicates the number of heavy (carbon/ nitrogen/oxygen) ions present. The bottom panel represents the percentage occurrence by flyby, with the same group definitions as the top panel. The percentage occurrence is by flyby, for example the large peak for the T59 flyby in the C18 group occurs in 44\% of the 96 sweeps examined. The vertical error bars in the top panel shown are three times the standard error relating to Poisson counting statistics, meaning there is a $99 \%$ probability that the number of occurrences lies within this range. The horizontal error bars are a combination of the uncertainty resulting from the energy resolution and the uncertainty from a $1 \mathrm{u} / \mathrm{q}$ binning.

The $\mathrm{C} 20$ and $\mathrm{C} 21$ groups have major peaks but also display minor peaks and the troughs between groups are not as evident. At these masses, the $12-14 \mathrm{u} / \mathrm{q}$ spacing trend breaks for $\mathrm{C} 20$, with a $16 \mathrm{u} / \mathrm{q}$ gap between $\mathrm{C} 19$ and $\mathrm{C} 20$ and a $9 \mathrm{u} / \mathrm{q}$ gap between $\mathrm{C} 20$ and the $\mathrm{C} 21$ major peaks. However as there are uncertainties of $\pm 3 \mathrm{u} / \mathrm{q}$ due to the energy resolution of IBS at these masses, it is plausible that the spacing is closer to 12 or
$14 \mathrm{u} / \mathrm{q}$. Alternatively, there is a minor peak in the $\mathrm{C} 20$ group at $253 \mathrm{u} / \mathrm{q}$, which would correspond to 12 and $13 \mathrm{u} / \mathrm{q}$ gaps between the $\mathrm{C} 20$ peak and its neighboring groups.

Above $270 \mathrm{u} / \mathrm{q}$ no clear peak and trough structure can be seen in Figure 6. Several significant peaks do exist, one such peak is seen at $280 \mathrm{u} / \mathrm{q}$ that would be associated with an ion containing 22 heavy atoms. At the highest masses studied here 


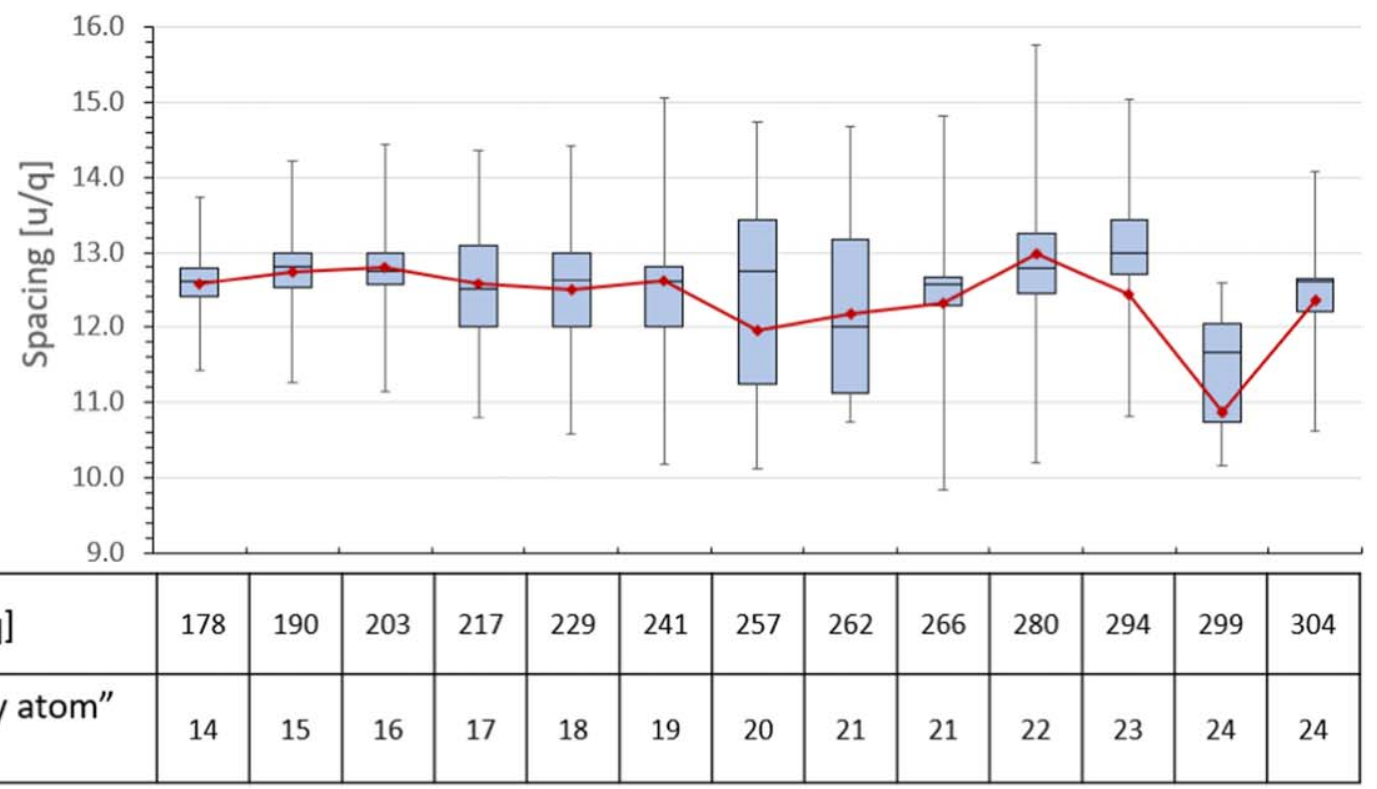

Figure 7. A box and whisker plot demonstrating the mass spacing between the significant observed peaks under the assumption of a number of "heavy atom" (carbon/ nitrogen/oxygen) in a molecular ion. This is calculated by finding the mass difference between pairs of peaks and dividing through by the difference in "heavy atoms". The mean spacing is plotted in red and is largely in the 12 and $13 \mathrm{u} / \mathrm{q}$ range. The box shown represents the interquartile range of the peak spacing along with the median. The low mean spacing of $11 \mathrm{u} / \mathrm{q}$ for the $299 \mathrm{u} / \mathrm{q}$ peak is due to the close neighboring masses at 294 and $304 \mathrm{u} / \mathrm{q}$, a similar effect can be seen for the 257 and 262 u/q peaks.

peaks are seen at $294 \pm 3,299 \pm 3$ and $304 \pm 3 \mathrm{u} / \mathrm{q}$. These peaks however do not have a distinct gap between them due to the uncertainties in measurement. Given the range of masses, it is likely there are multiple peaks and these are likely associated with ions containing 23 or 24 heavy atoms.

\subsubsection{Peak Spacing}

Further analysis of the mass spacing between peaks was performed to aid the understanding of growth pathways. This was done by finding the mass difference between each possible pair of peaks and dividing each mass difference by the number of assumed heavy atoms, for example, the mass difference for the 178 and $217 \mathrm{u} / \mathrm{q}$ peaks is $39 \mathrm{u} / \mathrm{q}$ and the difference in assumed heavy atoms is 3 , generating a peak spacing of $13 \mathrm{u} /$ q. This is repeated for all possible peak pairs and then the peak spacing is averaged. The results from this can be seen as a box and whisker plot in Figure 7, with the mean plotted in red. The lower and upper bounds of the whiskers are due to the combined uncertainty from both peak measurements. For example, the 203 and $217 \mathrm{u} / \mathrm{q}$ peaks both have an uncertainty of $\pm 2 \mathrm{u} / \mathrm{q}$, meaning the peak spacing for this pair could be between 10 and $18 \mathrm{u} / \mathrm{q}$. The value shown for the lower bound is the average of this minimum spacing across all peak pairs, a similar calculation gives the value for the upper bound. Some peaks have large interquartile ranges such as 257,262 , and 299 $\mathrm{u} / \mathrm{q}$, these are caused by neighboring peaks with small mass differences. These peaks could also be indicative of a molecule containing a heavier atom than carbon, such as nitrogen or oxygen, which would then affect the spacing between the peaks.

The mean spacing across all peaks is $12.4 \mathrm{u} / \mathrm{q}$ and the lower to upper quartile range typically covers the $12-13 \mathrm{u} / \mathrm{q}$. These masses would be consistent with a $\mathrm{C}$ or $\mathrm{CH}$ addition to the molecular ions.

\section{Discussion}

Many structures have been hypothesized for the large molecular ions in Titan's ionosphere. These have included polyacetylene, polyynes, cyanopolyynes (Wilson \& Atreya 2003; Lavvas et al. 2008a, 2008b; Vuitton et al. 2019). ( $\mathrm{HCN})_{\mathrm{n}}$ polymers have been proposed (Wilson \& Atreya 2003), as well as $\mathrm{HC}_{3} \mathrm{~N} / \mathrm{C}_{2} \mathrm{H}_{2}$ copolymers (Lebonnois et al. 2002; Lavvas et al. 2008b). PAHs and PANHs have been proposed as well (LópezPuertas et al. 2013; Zhao et al. 2018), resulting from the detection of benzene in Titan's upper atmosphere (Waite et al. 2007). Amines and imine polymers have been proposed to contribute to Titan's haze due to either the prerequisite monomers being found in Titan's atmosphere or the molecules being detected in tholin experiments (Vuitton et al. 2006; Cable et al. 2014; Skouteris et al. 2015). Fullerenes have also been proposed to exist (Sittler et al. 2020).

For assessing the composition of the ion peaks, we compare the masses associated with the ion peaks, with the masses consistent with different structures. This includes those structures mentioned above as well as other possible structures such as long aliphatic hydrocarbons with different levels of saturation. These aliphatic hydrocarbon chains include alkanes, alkenes, dienes, trienes, and alkynes. A table summarizing the comparison of peaks to possible structures is shown in Figure 8. Combinations of aliphatic hydrocarbons and various polymers can explain the observed ion peaks but the chemical structures that are consistent with all peaks are Polycyclic Aromatic Compounds (PACs). Furthermore, chemical structures such as $(\mathrm{HCN})_{n}$ polymers for example, are consistent with peaks for $n=7,8,9$, and 11, but are not present for $n=10$, which is unlikely to occur. This does not rule out the presence of aliphatic compounds but rather that the most abundant ions observed in this study are consistent with PACs. PACs represent a combination of PAH and/or polycyclic aromatic heterocycles containing nitrogen. Oxygen-bearing polycyclic aromatic molecules are also possible. There are also likely 


\begin{tabular}{|c|c|c|c|c|c|c|c|c|c|c|c|c|c|c|c|}
\hline & & & \multicolumn{13}{|c|}{ Mass [u/q] } \\
\hline & & Formula & $178_{-2}^{+2}$ & $190_{-2}^{+2}$ & $203+2$ & $217_{-2}^{+2}$ & $229 \pm 2$ & $241_{-3}^{+3}$ & $257_{-3}^{+3}$ & $262_{-3}^{+3}$ & $266_{-3}^{+3}$ & $280_{-3}^{+3}$ & $294_{-3}^{+3}$ & $299_{-3}^{+3}$ & $304_{-3}^{+3}$ \\
\hline \multirow{4}{*}{$\begin{array}{l}\text { Ringed } \\
\text { structures }\end{array}$} & $\begin{array}{l}\text { Polycyclic } \\
\text { Aromatic } \\
\text { Compounds }\end{array}$ & $\begin{array}{l}\mathrm{C}_{x} \mathrm{H}_{y} \\
\mathrm{C}_{x} \mathrm{H}_{y} \mathrm{~N}_{2} \\
\mathrm{C}_{x} \mathrm{H}_{y} \mathrm{O}_{2}\end{array}$ & $\begin{array}{l}\mathrm{C}_{14} \mathrm{H}_{9} \\
\mathrm{C}_{14} \mathrm{H}_{10} \\
\mathrm{C}_{14} \mathrm{H}_{12} \\
\mathrm{C}_{13} \mathrm{H}_{9} \mathrm{~N} \\
\mathrm{C}_{12} \mathrm{H}_{8} \mathrm{~N}_{2}\end{array}$ & $\begin{array}{l}\mathrm{C}_{15} \mathrm{H}_{10} \\
\mathrm{C}_{15} \mathrm{H}_{12}\end{array}$ & $\begin{array}{l}\mathrm{C}_{16} \mathrm{H}_{10} \\
\mathrm{C}_{16} \mathrm{H}_{11} \\
\mathrm{C}_{16} \mathrm{H}_{12} \\
\mathrm{C}_{15} \mathrm{H}_{9} \mathrm{~N}\end{array}$ & $\begin{array}{l}\mathrm{C}_{17} \mathrm{H}_{11} \\
\mathrm{C}_{17} \mathrm{H}_{14} \\
\mathrm{C}_{16} \mathrm{H}_{10} \mathrm{O} \\
\mathrm{C}_{16} \mathrm{H}_{11} \mathrm{O}\end{array}$ & $\begin{array}{c}\mathrm{C}_{18} \mathrm{H}_{12} \\
\mathrm{C}_{17} \mathrm{H}_{11} \mathrm{~N} \\
\mathrm{C}_{16} \mathrm{H}_{10} \mathrm{~N}_{2}\end{array}$ & $\begin{array}{l}\mathrm{C}_{19} \mathrm{H}_{11} \\
\mathrm{C}_{19} \mathrm{H}_{12} \\
\mathrm{C}_{19} \mathrm{H}_{14} \\
\mathrm{C}_{19 \mathrm{H}_{16}} \\
\mathrm{C}_{19} \mathrm{H}_{24}\end{array}$ & $\begin{array}{l}\mathrm{C}_{20} \mathrm{H}_{14} \\
\mathrm{C}_{20} \mathrm{H}_{16}\end{array}$ & $\mathrm{C}_{21} \mathrm{H}_{13}$ & $\mathrm{C}_{21} \mathrm{H}_{13}$ & $\begin{array}{l}\mathrm{C}_{22} \mathrm{H}_{14,16} \\
\mathrm{C}_{21} \mathrm{H}_{13} \mathrm{~N}\end{array}$ & $\mathrm{C}_{23} \mathrm{H}_{15-22}$ & $\begin{array}{l}\mathrm{C}_{24} \mathrm{H}_{12} \\
\mathrm{C}_{24} \mathrm{H}_{14} \\
\mathrm{C}_{23} \mathrm{H}_{11} \mathrm{~N} \\
\mathrm{C}_{23} \mathrm{H}_{12} \mathrm{~N}\end{array}$ & $\begin{array}{l}\mathrm{C}_{24} \mathrm{H}_{14} \\
\mathrm{C}_{24} \mathrm{H}_{16} \\
\mathrm{C}_{23} \mathrm{H}_{11} \mathrm{~N} \\
\mathrm{C}_{23} \mathrm{H}_{12} \mathrm{~N} \\
\mathrm{C}_{23} \mathrm{H}_{13} \mathrm{~N}\end{array}$ \\
\hline & $\begin{array}{l}\text { Graphite/ } \\
\text { Graphene }\end{array}$ & $C_{x}$ & $C_{15}$ & $C_{16}$ & $C_{17}$ & $\mathrm{C}_{18}$ & $C_{19}$ & $\mathrm{C}_{20}$ & & $\mathrm{C}_{22}$ & $\mathrm{C}_{22}$ & & & $\mathrm{C}_{25}$ & \\
\hline & Fullerene & $C_{20} \& C_{22}$ & & & & & & $\mathrm{C}_{20}$ & & $c_{22}$ & $c_{22}$ & & & & \\
\hline & Cycloalkane & $\mathrm{C}_{x} \mathrm{H}_{2 x}$ & & & & & & $\mathrm{C}_{13} \mathrm{H}_{34}$ & & & $\mathrm{C}_{19} \mathrm{H}_{38}$ & $\mathrm{C}_{20} \mathrm{H}_{40}$ & $\mathrm{C}_{21} \mathrm{H}_{42}$ & & \\
\hline \multirow{9}{*}{$\begin{array}{l}\text { Nitrogen- } \\
\text { bearing } \\
\text { polymers }\end{array}$} & $\mathrm{CN}$ polymer & $(\mathrm{CN})_{\mathrm{x}}$ & & & & & & & $\mathrm{C}_{10} \mathrm{~N}_{10}$ & $\mathrm{C}_{10 \mathrm{~N}_{10}}$ & & & & & \\
\hline & HCN polymer & $(\mathrm{HCN})_{x}$ & & $\mathrm{H}_{7} \mathrm{C}_{7} \mathrm{~N} 7$ & & $\mathrm{H}_{8} \mathrm{C}_{8} \mathrm{~N}_{8}$ & & $\mathrm{H}_{9} \mathrm{C}_{9} \mathrm{~N}_{9}$ & & & & & $\mathrm{H}_{11} \mathrm{C}_{11} \mathrm{~N}_{11}$ & $\mathrm{H}_{11} \mathrm{C}_{11} \mathrm{~N}_{11}$ & \\
\hline & $\begin{array}{l}\mathrm{HC}_{3} \mathrm{~N} / \mathrm{C}_{2} \mathrm{H}_{2} \\
\text { copolymer }\end{array}$ & $\left(\mathrm{HC}_{3} \mathrm{~N}\right)_{\times}\left(\mathrm{C}_{2} \mathrm{H}_{2}\right)_{\mathrm{Y}}$ & $\begin{array}{l}\mathrm{C}_{11} \mathrm{H}_{5} \mathrm{~N}_{3} \\
\mathrm{C}_{22} \mathrm{H}_{8} \mathrm{~N}_{2}\end{array}$ & & $\begin{array}{l}\mathrm{C}_{12} \mathrm{H}_{4} \mathrm{~N}_{4} \\
\mathrm{C}_{13} \mathrm{H}_{7} \mathrm{~N}_{3}\end{array}$ & & $\begin{array}{l}\mathrm{C}_{14} \mathrm{H}_{6} \mathrm{~N}_{4} \\
\mathrm{C}_{15} \mathrm{H}_{9} \mathrm{~N}_{3}\end{array}$ & & $\begin{array}{l}\mathrm{C}_{15} \mathrm{H}_{5} \mathrm{~N}_{5} \\
\mathrm{C}_{16} \mathrm{H}_{8} \mathrm{~N}_{4} \\
\mathrm{C}_{17} \mathrm{H}_{11} \mathrm{~N}_{3} \\
\mathrm{C}_{18} \mathrm{H}_{14} \mathrm{~N}_{2} \\
\mathrm{C}_{19} \mathrm{H}_{17} \mathrm{~N}\end{array}$ & $\mathrm{C}_{19} \mathrm{H}_{17} \mathrm{~N}$ & & $\begin{array}{l}\mathrm{C}_{17} \mathrm{H}_{7} \mathrm{~N}_{5} \\
\mathrm{C}_{18} \mathrm{H}_{10} \mathrm{~N}_{4} \\
\mathrm{C}_{19} \mathrm{H}_{13} \mathrm{~N}_{3}\end{array}$ & & & $\begin{array}{l}\mathrm{C}_{18} \mathrm{H}_{6} \mathrm{~N}_{6} \\
\mathrm{C}_{19} \mathrm{H}_{9} \mathrm{~N}_{5}\end{array}$ \\
\hline & $\mathrm{C}_{x} \mathrm{H}_{3} \mathrm{~N}_{x-2}$ & $\mathrm{C}_{x} \mathrm{H}_{3} \mathrm{~N}_{x-2}$ & & & & & & & & $\mathrm{C}_{11} \mathrm{H}_{3} \mathrm{~N}_{9}$ & & & & & \\
\hline & $\mathrm{C}_{x} \mathrm{~N}$ & $C_{x} N$ & & & & $\mathrm{C}_{17} \mathrm{~N}$ & $\mathrm{C}_{18} \mathrm{~N}$ & $\mathrm{C}_{19} \mathrm{~N}$ & $\mathrm{C}_{20} \mathrm{~N}$ & & $\mathrm{C}_{21} \mathrm{~N}$ & $\mathrm{C}_{22} \mathrm{~N}$ & & $\mathrm{C}_{24} \mathrm{~N}$ & $\mathrm{C}_{24} \mathrm{~N}$ \\
\hline & $\mathrm{HC}_{x} \mathrm{~N}$ & $\mathrm{HC}_{2} \mathrm{~N}$ & & & & $\mathrm{HC}_{17} \mathrm{~N}$ & $\mathrm{HC}_{18} \mathrm{~N}$ & $\mathrm{HC}_{19} \mathrm{~N}$ & $\mathrm{HC}_{20} \mathrm{~N}$ & & $\mathrm{HC}_{21} \mathrm{~N}$ & $\mathrm{HC}_{22} \mathrm{~N}$ & $\mathrm{HC}_{23} \mathrm{~N}$ & & $\mathrm{HC}_{24} \mathrm{~N}$ \\
\hline & $\mathrm{C}_{x} \mathrm{~N}_{2}$ & $\mathrm{C}_{x} \mathrm{~N}_{2}$ & & & & & & $\mathrm{C}_{18} \mathrm{~N}_{2}$ & $\mathrm{C}_{19} \mathrm{~N}_{2}$ & & $\mathrm{C}_{20} \mathrm{~N}_{2}$ & $\mathrm{C}_{21} \mathrm{~N}_{2}$ & $\mathrm{C}_{22} \mathrm{~N}_{2}$ & & $\mathrm{C}_{23} \mathrm{~N}_{2}$ \\
\hline & Linear amine & $\mathrm{C}_{x} \mathrm{H}_{2 x+3} \mathrm{~N}$ & & & & & $\mathrm{C}_{15} \mathrm{H}_{33} \mathrm{~N}$ & & $\mathrm{C}_{17} \mathrm{H}_{37} \mathrm{~N}$ & & $\mathrm{C}_{18} \mathrm{H}_{39} \mathrm{~N}$ & $\mathrm{C}_{19} \mathrm{H}_{41} \mathrm{~N}$ & $\mathrm{C}_{20} \mathrm{H}_{43} \mathrm{~N}$ & $\mathrm{C}_{20} \mathrm{H}_{43} \mathrm{~N}$ & \\
\hline & $\begin{array}{c}\text { Methanimine } \\
\text { polymer }\end{array}$ & $\left(\mathrm{CH}_{2} \mathrm{NH}\right)_{x}$ & & & $\mathrm{C}_{7} \mathrm{H}_{21} \mathrm{~N}_{7}$ & & & & & $\mathrm{C}_{9} \mathrm{H}_{27} \mathrm{~N}_{9}$ & & & & & \\
\hline \multirow{7}{*}{$\begin{array}{l}\text { Aliphatic } \\
\text { Hydro } \\
\text { carbons }\end{array}$} & $\mathrm{C}_{x} \mathrm{H}_{2}$ & $\mathrm{C}_{x} \mathrm{H}_{2}$ & & & & $\mathrm{C}_{18} \mathrm{H}_{2}$ & $\mathrm{C}_{19} \mathrm{H}_{2}$ & $\mathrm{C}_{20} \mathrm{H}_{2}$ & $\mathrm{C}_{21} \mathrm{H}_{2}$ & & $\mathrm{C}_{22} \mathrm{H}_{2}$ & $\mathrm{C}_{23} \mathrm{H}_{2}$ & & $\mathrm{C}_{25} \mathrm{H}_{2}$ & $\mathrm{C}_{25} \mathrm{H}_{2}$ \\
\hline & Polyacetylene & $\left(\mathrm{C}_{2} \mathrm{H}_{2}\right)_{\mathrm{x}}$ & & & & & & & $\mathrm{C}_{20} \mathrm{H}_{20}$ & $\mathrm{C}_{20} \mathrm{H}_{20}$ & & & & & \\
\hline & Alkane & $\mathrm{C}_{\mathrm{x}} \mathrm{H}_{2 \mathrm{x}+2}$ & & & & & & $\mathrm{C}_{17 \mathrm{H}_{36}}$ & $\mathrm{C}_{18} \mathrm{H}_{38}$ & & $\mathrm{C}_{19} \mathrm{H}_{40}$ & $\mathrm{C}_{20} \mathrm{H}_{42}$ & $\mathrm{C}_{21} \mathrm{H}_{44}$ & $\mathrm{C}_{21} \mathrm{H}_{44}$ & \\
\hline & Alkene & $\mathrm{C}_{x} \mathrm{H}_{2 \mathrm{x}}$ & & & & & & $\mathrm{C}_{17} \mathrm{H}_{34}$ & & & $\mathrm{C}_{19} \mathrm{H}_{38}$ & $\mathrm{C}_{20} \mathrm{H}_{40}$ & $\mathrm{C}_{21} \mathrm{H}_{42}$ & & \\
\hline & Diene & $\mathrm{C}_{x} \mathrm{H}_{2 \times 2}$ & $\mathrm{C}_{13} \mathrm{H}_{24}$ & & & & & & & $\mathrm{C}_{19} \mathrm{H}_{36}$ & $\mathrm{C}_{19} \mathrm{H}_{36}$ & $\mathrm{C}_{20} \mathrm{H}_{38}$ & $\mathrm{C}_{21} \mathrm{H}_{40}$ & & $\mathrm{C}_{22} \mathrm{H}_{42}$ \\
\hline & Triene & $\mathrm{C}_{x} \mathrm{H}_{2 \times-4}$ & $\mathrm{C}_{13} \mathrm{H}_{22}$ & $\mathrm{C}_{14} \mathrm{H}_{24}$ & & & & & & $\mathrm{C}_{19} \mathrm{H}_{34}$ & & & & & $\mathrm{C}_{22} \mathrm{H}_{40}$ \\
\hline & Alkyne & $\mathrm{C}_{x} \mathrm{H}_{2 \times-2}$ & $\mathrm{C}_{13} \mathrm{H}_{24}$ & & & & & & & $\mathrm{C}_{19} \mathrm{H}_{36}$ & $\mathrm{C}_{19} \mathrm{H}_{36}$ & $\mathrm{C}_{20} \mathrm{H}_{3 \mathrm{~B}}$ & $\mathrm{C}_{21} \mathrm{H}_{40}$ & & $\mathrm{C}_{22} \mathrm{H}_{42}$ \\
\hline
\end{tabular}

Figure 8. Table showing what structures are consistent with significant peaks. The structures are broken into three groups and highlighted in different colors for clarity: ringed structures containing aromatic and cyclic molecules, nitrogen-bearing aliphatic molecules and aliphatic hydrocarbon molecules. Any molecule that lies within the mass uncertainty associated with a peak is considered plausible. Polycyclic Aromatic Compounds are consistent with all observed ion peaks, followed by a graphite- or graphene- like structure, consistent with nine of the thirteen observed peaks. The list of polycyclic aromatic molecules considered are from the NASA Ames PAH IR database (except for the $294 \mathrm{u} / \mathrm{q}$ peak) and should be viewed as not-exhaustive.

methylene substituted derivatives of these compounds, as proposed in Ali et al. (2015).

PACs possibly have a role in the formation of aerosols (Lavvas et al. 2011). Early experiments found that Titan tholin analogs contain PAHs (Sagan et al. 1993) and also that PAHs may adsorb onto the tholins. Later studies have also found PANHs and PAHs in Titan tholin analogs (Trainer et al. 2013; Yoon et al. 2014; Mahjoub et al. 2016; Sciamma-O'Brien et al. 2017). Gautier et al. (2017) discuss how aerosol growth is affected depending on the number of aromatic rings in the reactant composition, finding that benzene and pyridine caused production of co-polymeric structures while double-ringed aromatic produced quasi-pure polymeric structures. Other studies have also investigated the impact of ions interacting with charged aerosols, demonstrating that they contribute to the growth of these particles (Lavvas et al. 2013). These findings indicate that the composition of Titan's aerosols is likely affected by the composition of the positive PAC ions studied here.

Westlake et al. (2014) examined three hypotheses for the production of high-mass ions in Titan's ionosphere. They concluded that the most viable method for creating the large molecules were through ion-molecule reactions with neutral acetylene, ethylene, and hydrogen cyanide. Ali et al. (2015) further investigated the cation, anion, and neutral chemistry that could be present in Titan's ionosphere through ionmolecule reactions. Low-temperature formation pathways of PAHs through radical-neutral reactions have been shown to exist for molecules with up to four six-membered rings (Zhao et al. 2018).

Comparing the findings presented here with the ionmolecule reactions proposed in Westlake et al. (2014) and Ali et al. (2015) we find the ion group peak masses agree with the expected masses resulting from ion-molecule reactions. Furthermore, comparing with proposed neutral PAHs/PANHs from López-Puertas et al. (2013), we find the reported neutral molecules have comparable masses, suggesting ionization and electron recombination are a factor. These two comparisons suggest a coupling between the cationic and neutral phases at the studied mass range.

\subsection{Ion Mass Group Composition}

Here we discuss the composition of the positive ions and a possible growth mechanism. The $\mathrm{C} 14$ and $\mathrm{C} 15$ group peaks have masses consistent with cationic three ringed PACs. Examining the $\mathrm{C} 14$ group across all flybys, the major peak lies between 176 and $181 \mathrm{u} / \mathrm{q}$ in the IBS data. Ali et al. (2015) suggested hydrocarbon cations of $\mathrm{C}_{14} \mathrm{H}_{9}^{+}, \mathrm{C}_{14} \mathrm{H}_{11}^{+}$and $\mathrm{C}_{14} \mathrm{H}_{13}^{+}$ as well as nitrogen-bearing $\mathrm{C}_{13} \mathrm{H}_{10} \mathrm{~N}^{+}$and $\mathrm{C}_{13} \mathrm{H}_{12} \mathrm{~N}^{+}$ions. These molecules lie within the 176 and $181 \mathrm{u} / \mathrm{q}$ range given the associated errors, meaning we cannot distinguish between the PAHs and nitrogen-containing PACs. Similarly, the cations in the $\mathrm{C} 16, \mathrm{C} 17$, and $\mathrm{C} 18$ groups can be associated with four ringed PAC cations and the $\mathrm{C} 19, \mathrm{C} 20$, and $\mathrm{C} 21$ with five ringed PAC cations. 


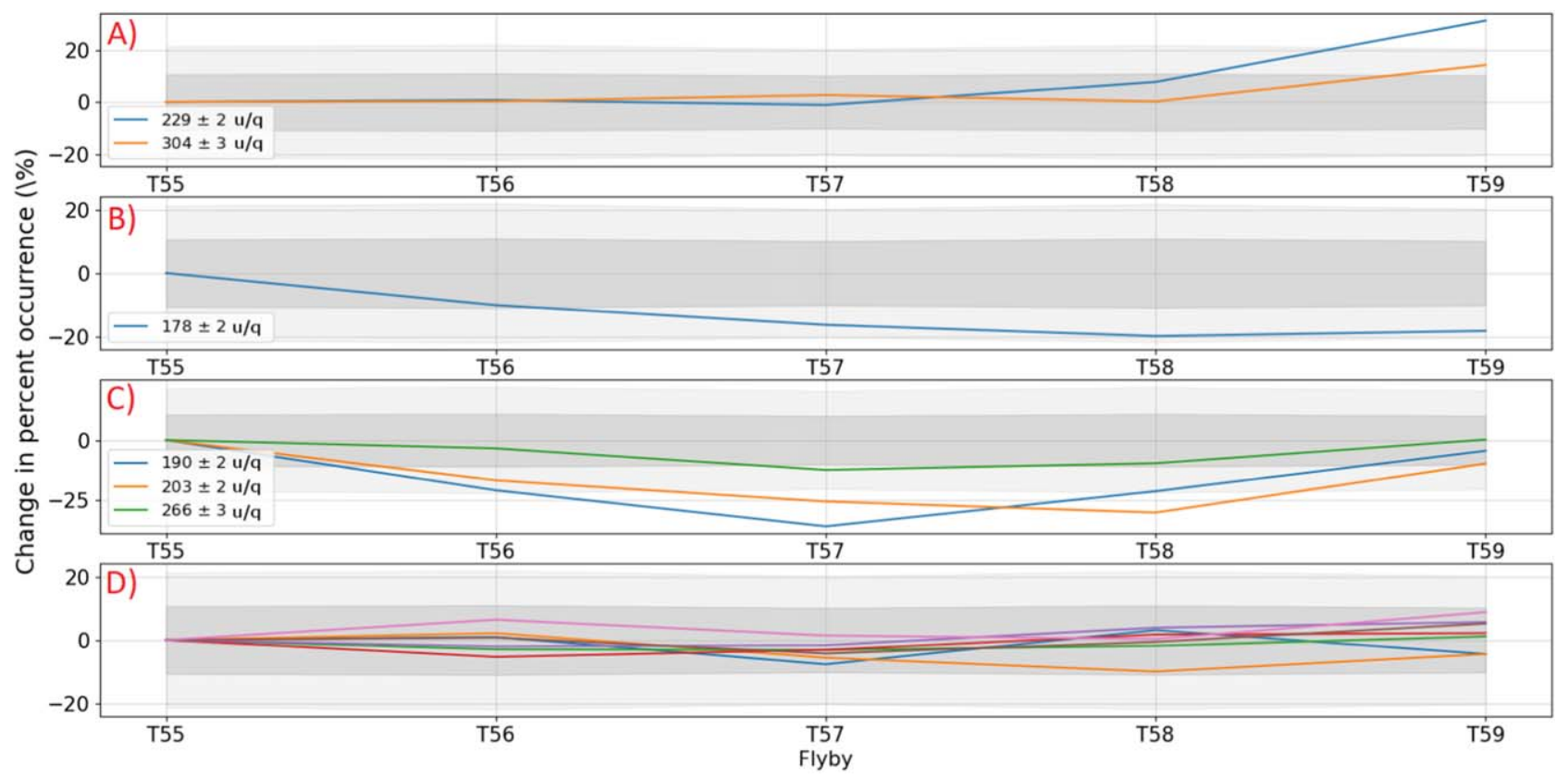

Figure 9. Change in percent occurrence of the observed peaks, as compared with T55. The uncertainties are Poisson counting statistics, with the dark gray and light gray regions representing one and two times the standard deviation respectively. The peaks are categorized into four groups, panel (A) shows peaks which occurred more frequently under illuminated conditions. Conversely, panel (B) shows a peak which occurred more frequently under unilluminated conditions. Panel (C) shows the peaks which had a minimum during the flybys and panel (D) are the remaining seven observed peaks that show no clear variation, with all points lying within one standard deviation.

The C15 group frequently occurs in all flybys generating a strong peak at $190 \pm 2 \mathrm{u} / \mathrm{q}$. Ali et al. (2015) describe the mechanism of substituting $\mathrm{CH}_{2}^{+}$in place of a hydrogen atom in a neutral PAC to generate cations, this would increase the mass of the ion by $13 \mathrm{u} / \mathrm{q}$, consistent with our peak spacing finding of 12 to $13 \mathrm{u} / \mathrm{q}$. Subsequent reactions with neutral ethylene creates larger cations alongside ejection of one or two $\mathrm{H}_{2}$ molecules. A similar mechanism is also proposed by Westlake et al. (2011), who investigated both ion-molecule reactions with neutral acetylene and ethylene.

The same $\mathrm{CH}_{2}^{+}$substitution mechanism can be applied to generate all observed ion group peaks. From Figure 8 for example, possible growth chains of $\mathrm{CH}_{2}^{+}$substitutions could be $\mathrm{C}_{14} \mathrm{H}_{9} \rightarrow \mathrm{C}_{15} \mathrm{H}_{10}^{+}$followed by $\mathrm{C}_{15} \mathrm{H}_{10} \rightarrow \mathrm{C}_{16} \mathrm{H}_{11}^{+}$. These chains could also exist at the upper end of the studied mass range as well, $\mathrm{C}_{20} \mathrm{H}_{14} \rightarrow \mathrm{C}_{21} \mathrm{H}_{13}^{+}$alongside a $\mathrm{H}_{2}$ ejection followed by $\mathrm{C}_{21} \mathrm{H}_{13} \rightarrow \mathrm{C}_{22} \mathrm{H}_{14}^{+}$. These chains could similarly occur for nitrogen- or oxygen- bearing PACs. Although this growth pathway is consistent with the observed peak spacing it does not rule out other reactions occurring with PAC cations.

Oxygen ions entering the ionosphere and the presence of $\mathrm{H}_{2} \mathrm{O}, \mathrm{CO}_{2}$ and $\mathrm{CO}$ (Cui et al. 2009; Hörst et al. 2012) imply that oxygen-bearing polycyclic aromatic molecules are plausible, although are likely to have a small contribution compared with PAHs or PANHs. These oxygen ions charge transfer with neutrals generated thermal $\mathrm{O}$ atoms (Vuitton et al. 2019) and interstellar medium experiments have found reaction pathways between atomic oxygen and the $\mathrm{C}_{10} \mathrm{H}_{8}^{+}$naphthalene cation (Lavvas et al. 1999a). Le Page et al. (1999b) studied reactions between various pyrene cations and atomic oxygen and found that $\mathrm{C}_{16} \mathrm{H}_{9} \mathrm{O}^{+}$and $\mathrm{C}_{16} \mathrm{H}_{10} \mathrm{O}^{+}$could be created. The reaction with $\mathrm{CO}$ could be significant and has been shown to incorporate oxygen into tholins in atmospheric simulation experiments (Fleury et al. 2014). Other reactions involving $\mathrm{OH}$, $\mathrm{H}_{2} \mathrm{O}$ and other oxygen-bearing molecules cannot be ruled out but are not explored here. The formation pathways and reaction rates for oxygen-bearing polycyclic aromatic molecules are poorly understood but their presence cannot be ruled out by this study.

\subsection{Variations between Flybys}

Examining the different characteristics for the five studied flybys: the closest approach altitudes were between 955 and $967 \mathrm{~km}$, the closest approach longitudes were within a 5 degree range and the closest approach local times were all close to 22:00. However, the SZA values range from 103 to 149, which is primarily due to the flyby latitude increasing from $-19^{\circ}$ during T55, to $-55^{\circ}$ during T59. There is also variation in the percentage occurrence of some observed peaks between different flybys. This could be a signature of varying production, loss, and transport rates of the ions associated with the peaks. Furthermore, it could be linked to neutral and anion chemistry that occurs, which varies between the day and nightside of Titan (Vuitton et al. 2019). Examining Figure 9, six of the thirteen significant peaks display clear variations. Some peaks occur more frequently with more solar radiation while one peak occurs less frequently. Furthermore, some peaks can be seen to occur less frequently in the transition between illuminated and unilluminated conditions.

From Figure 9, we can see that the $229 \pm 2$ and $304 \pm 3 \mathrm{u} / \mathrm{q}$ peaks occur more frequently in the T59 flyby. Examining the percentage occurrence of the $229 \mathrm{u} / \mathrm{q}$ peak in Figure 6, there is a 35\% increase for T59 compared with T55. The trend for the $304 \pm 3 \mathrm{u} / \mathrm{q}$ peak is not as clear, with the significant increase in occurrence occurring only during the T59 flyby.

In contrast, panel B) in Figure 9 shows the only example of a significant decrease in percent occurrence, associated with the $178 \pm 2 \mathrm{u} / \mathrm{q}$ peak in the $\mathrm{C} 14$ ion mass group. Between the dark T55 flyby and the illuminated T59 flyby the peak 
occurrence drops by around $20 \%$. The $\mathrm{C} 14$ group is the least frequently seen group in the 100-200 u/q range in both this study and Crary et al. (2009), which could be related to this observed variation.

The third panel in Figure 9 shows three peaks which have an occurrence minimum during the five studied flybys. The $190 \pm 2$ and $266 \pm 3 \mathrm{u} / \mathrm{q}$ peaks have a minimum percentage occurrence during the T57 flyby while $203 \pm 2 \mathrm{u} / \mathrm{q}$ minimum is during T58.

Due to Titan's extended atmosphere the effects of solar EUV radiation on ions are seen past the terminator, up to SZA values of $135^{\circ}$ at $1000 \mathrm{~km}$ (Ågren et al. 2009; Cui et al. 2009; Coates et al. 2009, 2011; Wellbrock et al. 2009, 2013; A. Wellbrock 2021, in preparation), although at high SZA values the solar radiation is attenuated by passing through more of Titan's atmosphere Cui et al. (2009) studied the diurnal variations of positive ions, finding that light ions were strongly depleted on the nightside while the heavy ions were moderately depleted and the most significant diurnal variations were seen at low altitudes. These depletions are linked to the loss of ion production from solar EUV radiation.

Similar to the light cations, light anions $(<50 \mathrm{u} / \mathrm{q})$ have been shown to have higher densities on the dayside (Wellbrock et al. 2012; Mihailescu et al. 2020; A. Wellbrock 2021, in preparation). On the other hand, Wellbrock et al. (2009), A. Wellbrock (2021, in preparation) and Coates et al. (2009, 2011) show that heavy anion densities under illuminated conditions past the terminator are lower than unilluminated conditions in the deeper nightside ionosphere, as observed during flybys such as T57. The higher densities of heavy anions in unilluminated conditions could provide a competing pathway to heavy cation production. This could be through higher anion production rates or through lower anion loss rates, an example of a loss process would be photodetachment. Photodetachment efficiency increases with ion size (Lavvas et al. 2013; Wellbrock et al. 2019), which would remove heavy anions from the dayside allowing for higher heavy cation densities. Ionization energy is the energy needed to remove an electron from a molecule while electron affinity is the amount of energy released when an electron is added to a molecule. There is a general trend of increasing electron affinity and decreasing ionization energy with increasing PAH mass (Christodoulides et al. 1984; Dabestani \& Ivanov 1999), meaning larger PAHs can more readily form positive or negative ions under favorable conditions.

Wellbrock et al. (2013) identified several mass groups of negative ions, with the 190-625 u/q mass group displaying the highest density of all groups at an average peak altitude of $1000 \mathrm{~km}$. The flybys in this study are at a similar altitude and the mass range studied covers this negative ion group.

Due to the complex cation-neutral-anion chemistry and lack of information on reaction rates at these high masses, we cannot distinguish between different factors such as anion chemistry, ion transport, and changing ion-neutral pathways. Future investigations that examine flybys in the noon/midnight regions would help identify photochemical effects. Furthermore, future chemical models could aid identification of these heavy molecular ions through examining recombination rates and ion-neutral reactions to see which ions are consistent with observed variations.

\subsection{Comparison with Neutral PACs in Titan's Atmosphere}

López-Puertas et al. (2013) studied an IR emission from Titan and applied a fitting algorithm to identify neutral PACs in the upper atmosphere. 7 of their 19 most abundant PACs lie in the $170-310 \mathrm{u} / \mathrm{q}$ mass range. These seven molecules are $\mathrm{C}_{13} \mathrm{H}_{9} \mathrm{~N}(179 \mathrm{u} / \mathrm{q}), \mathrm{C}_{12} \mathrm{H}_{8} \mathrm{~N}_{2}(180 \mathrm{u} / \mathrm{q}), \mathrm{C}_{14} \mathrm{H}_{16}(184 \mathrm{u} / \mathrm{q})$, $\mathrm{C}_{16} \mathrm{H}_{10} \mathrm{~N}_{2}(230 \mathrm{u} / \mathrm{q}), \mathrm{C}_{20} \mathrm{H}_{10}(250 \mathrm{u} / \mathrm{q}), \mathrm{C}_{20} \mathrm{H}_{14}(254 \mathrm{u} / \mathrm{q})$ and $\mathrm{C}_{22} \mathrm{H}_{16}(280 \mathrm{u} / \mathrm{q})$. These neutral molecules are in the even numbered mass groups: C14, C18, C20, and C22.

Three of these molecules are in the $\mathrm{C} 14$ group, $\mathrm{C}_{13} \mathrm{H}_{9} \mathrm{~N}$, $\mathrm{C}_{12} \mathrm{H}_{8} \mathrm{~N}_{2}$ and $\mathrm{C}_{14} \mathrm{H}_{16}$. The first two of these neutrals could be related to the major $\mathrm{C} 14$ peak in the IBS data at $178 \mathrm{u} / \mathrm{q}$. López-Puertas et al. (2013) reported $\mathrm{C}_{14} \mathrm{H}_{16}$ to be present at a low concentration and in this study we find a minor peak (percentage occurrence below 10\%) at $184 \pm 2 \mathrm{u} / \mathrm{q}$ that occurs in four of the studied flybys. This peak could result from the ionization of the reported $\mathrm{C}_{14} \mathrm{H}_{16}$ neutral.

$\mathrm{C}_{16} \mathrm{H}_{10} \mathrm{~N}_{2}$ is in the $\mathrm{C} 18$ group and could be related to the ion mass peak at $229 \mathrm{u} / \mathrm{q}$. The two molecules in the $\mathrm{C} 20$ group, $\mathrm{C}_{20} \mathrm{H}_{10}$ and $\mathrm{C}_{20} \mathrm{H}_{14}$, were some of the least abundant molecules reported by López-Puertas et al. (2013). The major peak in the C20 group is at $257 \pm 3 \mathrm{u} / \mathrm{q}$ with a minor peak at $253 \pm 3 \mathrm{u} / \mathrm{q}$. This puts both molecules within the error of the ion peak. However, there is no clear peak structure at $250 \mathrm{u} / \mathrm{q}$ with the region between 248 and $251 \mathrm{u} / \mathrm{q}$ being a trough between the C20 and C21 groups. This could indicate that we see a higher level of hydrogenation in the cationic phase.

Although we do not find clear structure for the C22 group, there is a peak at $280 \pm 3 \mathrm{u} / \mathrm{q}$ therefore a similar mass to the neutral $\mathrm{C}_{22} \mathrm{H}_{16}$ at $280 \mathrm{u} / \mathrm{q}$. This peak strongly occurs during the T58 and T59 flybys, peaking at $279 \mathrm{u} / \mathrm{q}$ and $280 \mathrm{u} / \mathrm{q}$ respectively.

In summary, from the comparison between the ionic and neutral phases, the masses of previously observed neutral PACs in Titan's atmosphere correlate with cations in the ionosphere. The only exception found was the neutral PAH $\mathrm{C}_{20} \mathrm{H}_{10}$. The comparisons between the observed abundant neutral molecules and the frequently occurring ion peaks indicate that there is a need for combined study of the neutral and cationic phases to fully characterize Titan's ionosphere. In addition, further study of what neutral PAHs exist in Titan's ionosphere could aid with interpretation in future ion compositional studies.

\section{Conclusions}

The composition of positive ions between 170 and $310 \mathrm{u} / \mathrm{q}$ has been examined during five CAPS actuator-fixed flybys that took place during 2009. The composition was investigated by examining how frequently a peak occurs at a given mass. Up to $275 \mathrm{u} / \mathrm{q}$ there is a clear ion group structure of peaks and troughs, where the peaks are ion masses with a high relative abundance. Conversely, the troughs are associated with ion of low relative abundance. Between 275 and $310 \mathrm{u} / \mathrm{q}$, several prominent peaks are found but with no clearly associated group structure. The identified ion peaks are consistent with various aliphatic compounds, however, polycylic aromatic compounds, such as PAHs/PANHs, are found to be consistent with all identified peaks. The spacing between peaks was found to be between 12 and $13 \mathrm{u} / \mathrm{q}$, with an average spacing of $12.4 \mathrm{u} / \mathrm{q}$ consistent with the addition of $\mathrm{C}$ or $\mathrm{CH}$.

Variation in the occurrence of prominent peaks indicates changes in the photochemistry, most likely due to differing 
solar radiation conditions, at the studied 170-310 u/q mass range. Comparisons with neutral PAHs/PANHs findings in the atmosphere reveal that the newly found ion peaks are found at similar masses to the abundant molecules in the neutral phase. This implies coupling between the ion and neutral phases at these masses.

These are the largest distinct positive ion groups reported so far in Titan's ionosphere. The discovery of these groups will aid future atmospheric chemical models of Titan through the identification of what heavy positive ions are prominent, aiding the understanding of which reaction pathways are plausible to create the previously found heavy negative ions and neutrals. The future Dragonfly mission to Titan will study the surface composition and prebiotic chemistry. Given that the complex organic compounds created in Titan's atmosphere form the particles that comprise the haze found at lower altitudes and that these particles are expected to fall onto the surface, understanding the origin of these organic compounds gives helpful insights into the interpretation of future results.

R. P. Haythornthwaite is supported by Science and Technology Facilities Council (STFC) studentship 2062537. A. J. Coates, G. H. Jones and A. Wellbrock acknowledge support from the STFC consolidated grant to UCLMSSL ST/ S000240/1. We acknowledge funding from ESA via the UK Space Agency for the Cassini CAPS Operations team. Work in the USA was supported by Southwest Research Institute internal funding. Cassini CAPS data are available from the NASA PDS service. We thank the reviewers for their helpful comments that have improved the paper.

Software: astropy (Astropy Collaboration et al. 2013, 2018), matplotlib (Caswell et al. 2020), NumPy (van der Walt et al. 2011), SciPy (Virtanen et al. 2020).

\section{ORCID iDs}

Richard P. Haythornthwaite (1) https://orcid.org/0000-00025836-2827

Andrew J. Coates (10) https://orcid.org/0000-0002-6185-3125 Geraint H. Jones (1) https://orcid.org/0000-0002-5859-1136

Anne Wellbrock (i) https://orcid.org/0000-0002-2861-7999

J. Hunter Waite (1) https://orcid.org/0000-0002-1978-1025

Véronique Vuitton (i) https://orcid.org/0000-0001-7273-1898

Panayotis Lavvas (i) https://orcid.org/0000-0002-5360-3660

\section{References}

Ågren, K., Wahlund, J. E., Garnier, P., et al. 2009, P\&SS, 57, 1821

Ali, A., Sittler, E., Chornay, D., Rowe, B., \& Puzzarini, C. 2015, P\&SS, 109,46

Astropy Collaboration, Price-Whelan, A. M., Sipőcz, B. M., et al. 2018, AJ, 156,123

Astropy Collaboration, Robitaille, T. P., Tollerud, E. J., et al. 2013, A\&A, 558, A33

Berry, J. L., Ugelow, M. S., Tolbert, M. A., \& Browne, E. C. 2019, ApJL, 885, L6

Cable, M., Hörst, S., He, C., et al. 2014, E\&PSL, 403, 99

Caswell, T. A., Droettboom, M., Lee, A., et al. 2020, matplotlib/matplotlib: REL: v3.2.2, Zenodo, doi:10.5281/zenodo. 3898017
Christodoulides, A., McCorkle, D., \& Christophorou, L. 1984, ElectronMolecule Interactions and Their Applications, Vol. 2 (Cambridge, MA: Academic Press), 423

Coates, A., Crary, F., Lewis, G., et al. 2007, GeoRL, 34, L24S05

Coates, A., Wellbrock, A., Lewis, G., et al. 2009, P\&SS, 57, 1866

Coates, A., Wellbrock, A., Lewis, G., et al. 2010, FaDi, 147, 293

Coates, A. J., Wahlund, J.-E., ren, K., et al. 2011, SSRv, 162, 85

Coustenis, A., Achterberg, R. K., Conrath, B. J., et al. 2007, Icar, 189, 35

Coustenis, A., Salama, A., Schulz, B., et al. 2003, Icar, 161, 383

Crary, F., Magee, B., Mandt, K., et al. 2009, P\&SS, 57, 1847

Cravens, T. E., Robertson, I. P., Waite, J. H., Jr., et al. 2006, GeoRL, 33, L07105

Cui, J., Galand, M., Yelle, R. V., et al. 2009, JGRA, 114, A06310

Cui, J., Yelle, R. V., Vuitton, V., et al. 2009, Icar, 200, 581

Dabestani, R., \& Ivanov, I. N. 1999, Photochem. Photobiol., 70, 10

Desai, R., Coates, A., Wellbrock, A., et al. 2017, ApJ, 844, L18

Dubois, D., Carrasco, N., Jovanovic, L., et al. 2020, Icar, 338, 113437

Fleury, B., Carrasco, N., Gautier, T., et al. 2014, Icar, 238, 221

Gautier, T., Sebree, J. A., Li, X., et al. 2017, P\&SS, 140, 27

Gurnett, D. A., Kurth, W. S., Kirchner, D. L., et al. 2004, SSRv, 114, 395

Hartle, R. E., Sittler, E. C., Neubauer, F. M., et al. 2006, GeoRL, 33, L08201

Hörst, S. M., Yelle, R. V., Buch, A., et al. 2012, AsBio, 12, 809

Lavvas, P., Sander, M., Kraft, M., \& Imanaka, H. 2011, ApJ, 728, 80

Lavvas, P., Yelle, R. V., Koskinen, T., et al. 2013, PNAS, 110, 2729

Lavvas, P. P., Coustenis, A., \& Vardavas, I. M. 1999a, IJMSp, 185, 949

Lavvas, P. P., Coustenis, A., \& Vardavas, I. M. 2008a, P\&SS, 56, 27

Lavvas, P. P., Coustenis, A., \& Vardavas, I. M. 2008b, P\&SS, 56, 67

Le Page, V., Keheyan, Y., Snow, T. P., \& Bierbaum, V. M. 1999b, IJMSp, 185,949

Lebonnois, S., Bakes, E., \& McKay, C. P. 2002, Icar, 159, 505

Lindal, G. F., Wood, G. E., Hotz, H. B., et al. 1983, Icar, 53, 348

López-Puertas, M., Dinelli, B. M., Adriani, A., et al. 2013, ApJ, 770, 132

Mahjoub, A., Schwell, M., Carrasco, N., et al. 2016, P\&SS, 131, 1

Mandt, K. E., Gell, D. A., Perry, M., et al. 2012, JGRE, 117, E10006

Mihailescu, T., Desai, R. T., Shebanits, O., et al. 2020, PSJ, 1, 50

Porco, C. C., Baker, E., Barbara, J., et al. 2005, Natur, 434, 159

Sagan, C., Khare, B. N., Thompson, W. R., et al. 1993, ApJ, 414, 399

Sciamma-O’Brien, E., Upton, K. T., \& Salama, F. 2017, Icar, 289, 214

Sittler, E. C., Cooper, J. F., Sturner, S. J., \& Ali, A. 2020, Icar, 344, 113246

Skouteris, D., Balucani, N., Faginas-Lago, N., Falcinelli, S., \& Rosi, M. 2015, A\&A, 584, A76

Trainer, M. G., Sebree, J. A., Yoon, Y. H., \& Tolbert, M. A. 2013, ApJL, 766, L4

Tyler, G. L., Eshleman, V. R., Anderson, J. D., et al. 1981, Sci, 212, 201

van der Walt, S., Colbert, S. C., \& Varoquaux, G. 2011, CSE, 13, 22

Vilppola, J. H., Tanskanen, P. J., Barraclough, B. L., \& McComas, D. J. 2001, RScI, 72, 3662

Virtanen, P., Gommers, R., Oliphant, T. E., et al. 2020, Nature Methods, 17,261

Vuitton, V., Yelle, R., Klippenstein, S., Hörst, S., \& Lavvas, P. 2019, Icar, 324,120

Vuitton, V., Yelle, R., \& McEwan, M. 2007, Icar, 191, 722

Vuitton, V., Yelle, R. V., \& Anicich, V. G. 2006, ApJL, 647, L175

Waite, J. H., Niemann, H., Yelle, R. V., et al. 2005, Sci, 308, 982

Waite, J. H., Young, D. T., Cravens, T. E., et al. 2007, Sci, 316, 870

Wellbrock, A., Coates, A., Jones, G., Lewis, G., \& Waite, J. 2013, GeoRL, 40,4481

Wellbrock, A., Coates, A. J., Jones, G. H., et al. 2009, AGUFM, 2009, P51G-1198

Wellbrock, A., Coates, A. J., Jones, G. H., et al. 2012, AGUFM, 2012, P21F-1898

Wellbrock, A., Coates, A. J., Jones, G. H., et al. 2019, MNRAS, 490, 2254

Westlake, J. H., Bell, J. M., Waite, J. H., Jr., et al. 2011, JGRA, 116, A03318

Westlake, J. H., Waite, J. H., Jr., Carrasco, N., Richard, M., \& Cravens, T. 2014, JGRA, 119, 5951

Wilson, E., \& Atreya, S. 2003, P\&SS, 51, 1017

Yoon, Y. H., Hörst, S. M., Hicks, R. K., et al. 2014, Icar, 233, 233

Young, D., Berthelier, J., Blanc, M., et al. 2004, SSRv, 114, 1

Zhao, L., Kaiser, R. I., Xu, B., et al. 2018, NatAs, 2, 973 